\title{
INFORMATION
}

\section{Animal stem cells: the engineering development front of 2018}

\author{
Wenye YUAN $(\bowtie)^{1}$, Jianxiang $\mathrm{XU}^{2}$, Chenying $\mathrm{LI}^{3}$, Lijuan $\mathrm{SHI}^{3}$, Aidong YANG ${ }^{1}$, Yan WANG ${ }^{1}, \mathrm{Lu} \mathrm{XING}^{1}$, \\ Shaozhong KANG \\ 1 Division of Scientific R\&D, China Agricultural University, Beijing 100193, China \\ 2 Division of Natural Science Academic Publishing, Higher Education Press, Beijing 100029, China \\ 3 Library, China Agricultural University, Beijing 100193, China \\ 4 Center for Agricultural Water Research in China, China Agricultural University, Beijing 100083, China
}

The Engineering Fronts reports are important guidelines for the future development directions of engineering science and technology. The Chinese Academy of Engineering (CAE) has been conducting studies relevant to Engineering Fronts for two years since 2017 , with the aim of offering academic guidance and assistance in decision making ${ }^{[1]}$. In collaboration with Clarivate Analytics (Philadelphia, PA, USA), Utilization Technology of Animal Stem Cells was selected as a key engineering development front for detailed interpretation using the literature data analysis, ThemeScape map analysis of Derwent Innovation (Fig. 1) and surveys using questionnaires.

Stem cells are a type of immature, undifferentiated cells that have the potential to regenerate various tissues and organs of the human body. Animal stem cells are a type of self-renewing pluripotent cells that were widely used in the basic research of animal medicine and the animal disease treatment. Under certain conditions, stem cells can be separated into different types of functional cells. Based on their developmental stage, stem cells can be divided into embryonic stem cells and somatic stem cells. Also, based on their differentiation potential, stem cells can be divided into three types: totipotent, pluripotent and unipotent stem cells. In the medical science, these cells are known as all-purpose cells.

Among the many types of adult stem cells, hematopoietic stem cells (HSCs) are a type of stem cells that were investigated in early studies on genetics, and are recognized to be effective in clinical applications. HSCs are selfrenewing and pluripotent adult stem cells that have the potential to differentiate into various blood cells, and are the most primitive type of cells in hemopoiesis, they are the source of all red blood cells, platelets and white blood cells (including granulocytes, monocytes and lymphocytes), sustaining lifelong hematopoiesis of mammals. HSCs are found in microsites within bone marrow. Therefore, HSC functions are regulated by various internal and external factors. HSC transplantation is used not only to treat hematopoietic malignancies, but also to treat other diseases, such as autoimmune and metabolic diseases. In addition, they are important in animal regenerative medicine. On this development front, the majority of patents are in the USA and China (Table 1). The USA accounted for two-thirds, occupying the leading position. In terms of core patent distribution by contributing institutions (Table 2), DuPont (Wilmington, DE, USA) had the highest number of patents, however, China Agricultural University had a higher number of core patent citations. The country collaboration diagrams (Fig. 2) indicate that Denmark and Switzerland and the USA cooperated extensively. The institution collaboration network diagram (Fig. 3) indicates that BROD (Broad Institute, Cambridge, MA, USA), MASI (Massachusetts Institute of Technology, Cambridge, MA, USA), and HARD (Harvard College, Cambridge, MA, USA) had the closest collaboration.

Received January 1, 2019

Correspondence: yuanwenye@cau.edu.cn

(C) The Author(s) 2019. Published by Higher Education Press. This is an open access article under the CC BY license (http://creativecommons.org/licenses/by/4.0) 


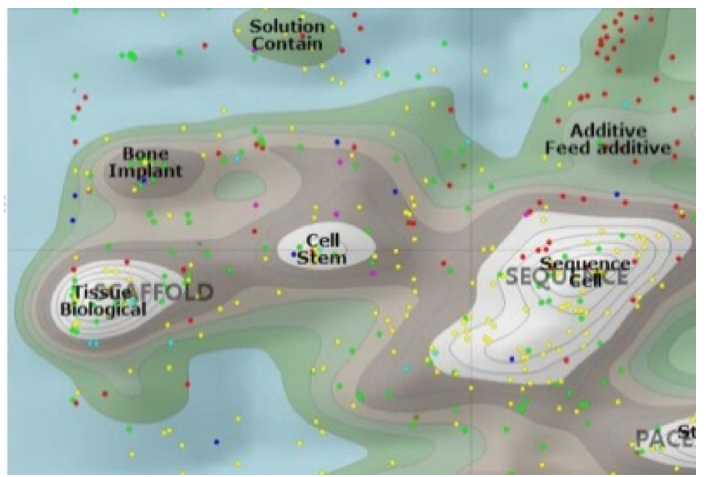

Fig. 1 Hotspot of stem cell on the ThemeScape patent map using Derwent Innovation data

Table 1 Countries with the greatest output of core patents on Utilization Technology of Animal Stem Cells in 2012-2017

\begin{tabular}{|c|c|c|c|c|c|c|}
\hline No. & Country & Published patents & Percentage of published patents $/ \%$ & Citations & Percentage of citations $/ \%$ & Citations per patent \\
\hline$\overline{1}$ & USA & 178 & 63.35 & 2876 & 67.96 & 16.16 \\
\hline 2 & China & 54 & 19.22 & 606 & 14.32 & 11.22 \\
\hline 3 & Denmark & 13 & 4.63 & 223 & 5.27 & 17.15 \\
\hline 4 & Netherlands & 11 & 3.91 & 180 & 4.25 & 16.36 \\
\hline 5 & France & 9 & 3.20 & 188 & 4.44 & 20.89 \\
\hline 6 & Japan & 9 & 3.20 & 98 & 2.32 & 10.89 \\
\hline 7 & Canada & 5 & 1.78 & 69 & 1.63 & 13.80 \\
\hline 8 & Germany & 5 & 1.78 & 121 & 2.86 & 24.20 \\
\hline 9 & UK & 5 & 1.78 & 56 & 1.32 & 11.20 \\
\hline 10 & Switzerland & 4 & 1.42 & 59 & 1.39 & 14.75 \\
\hline
\end{tabular}

Table 2 Institutions with the greatest output of core patents on the Utilization Technology of Animal Stem Cells in 2012-2017

\begin{tabular}{|c|c|c|c|c|c|c|c|}
\hline No. & Institution & Country & Published patents & $\begin{array}{c}\text { Percentage of } \\
\text { published patents } / \%\end{array}$ & Citations & $\begin{array}{c}\text { Percentage of } \\
\text { citations } / \%\end{array}$ & Citations per patent \\
\hline$\overline{1}$ & DUPO & USA & 20 & 7.12 & 331 & 7.82 & 16.65 \\
\hline 2 & MASI & USA & 16 & 5.69 & 421 & 9.95 & 26.31 \\
\hline 3 & BROD & USA & 15 & 5.34 & 412 & 9.74 & 27.47 \\
\hline 4 & HARD & USA & 12 & 4.27 & 268 & 6.33 & 22.33 \\
\hline 5 & REGN & USA & 12 & 4.27 & 169 & 3.99 & 14.08 \\
\hline 6 & STAM & Netherlands & 7 & 2.49 & 103 & 2.43 & 14.71 \\
\hline 7 & CECT & France & 6 & 2.14 & 145 & 3.43 & 24.17 \\
\hline 8 & Recombinetics Inc. & USA & 6 & 2.14 & 99 & 2.34 & 16.50 \\
\hline 9 & REGC & USA & 5 & 1.78 & 85 & 2.01 & 17.00 \\
\hline 10 & STRD & USA & 5 & 1.78 & 88 & 2.08 & 17.60 \\
\hline
\end{tabular}

Note: DUPO, DuPont Nutrition Biosciences ApS; MASI, Massachusetts Institute of Technology; BROD, Broad Institute; HARD, Harvard College; REGN, Regeneron Pharmaceuticals, Inc.; STAM, DSM Intellectual Property Assets Management; CECT, Cellectis; REGC, University of California; STRD, University of Leland Stanford Jr. 


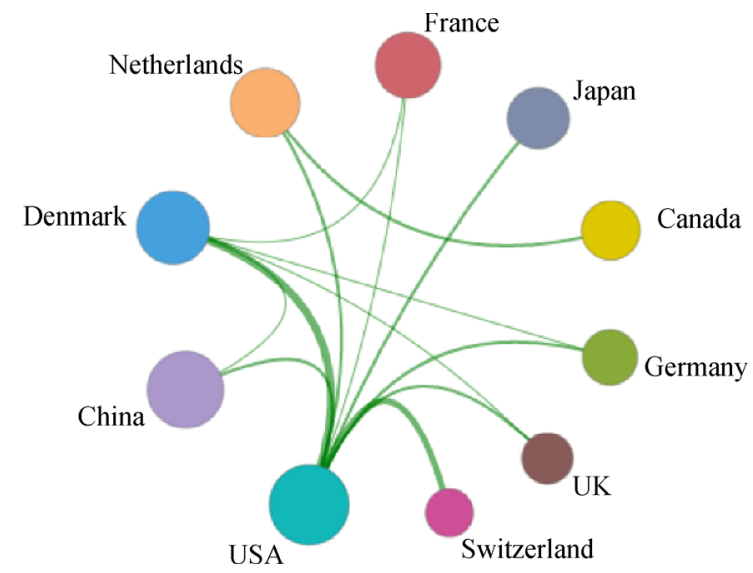

Fig. 2 Collaboration network among major countries in the engineering development front of Utilization Technology of Animal Stem Cells

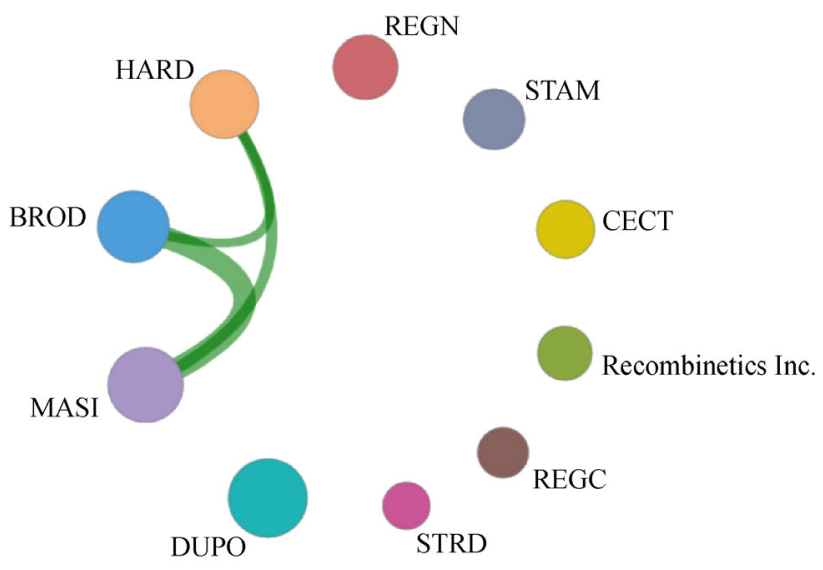

Fig. 3 Collaboration network among major institutions in the engineering development front of Utilization Technology of Animal Stem Cells. REGN, Regeneron Pharmaceuticals, Inc.; STAM, DSM Intellectual Property Assets Management; CECT, Cellectis; REGC, University of California; STRD, University of Leland Stanford Jr.; DUPO, DuPont Nutrition Biosciences ApS; MASI, Massachusetts Institute of Technology; BROD, Broad Institute; HARD, Harvard College.

Acknowledgements This report was completed with the support from the project, "Strategic consulting and research of global engineering focus," of the Chinese Academy of Engineering under the guidance and help of the project integration group. The processed data were kindly provided by Clarivate Analytics.

Compliance with ethics guidelines Wenye Yuan, Jianxiang Xu, Chenying Li, Lijuan Shi, Aidong Yang, Yan Wang, Lu Xing, and Shaozhong Kang declare that they have no conflicts of interest or financial conflicts to disclose.

This information does not contain any studies with human or animal subjects performed by any of the authors.

\section{Reference}

1. Cai F, Ji J M, Jiang Z Q, Mu Z R, Wu X, Zheng W J, Zhou W X, Tu S T, Qian X. Engineering Fronts in 2018. Engineering, 2018, 4(6): 748-753 